\title{
On the head morphology of Lepiceridae (Coleoptera: Myxophaga) and the systematic position of the family and suborder
}

\author{
ERIC ANTON ${ }^{1}$ and Rolf G. BEUTEL ${ }^{2}$ \\ Institut für Spezielle Zoologie und Evolutionsbiologie mit Phyletischem Museum, FSU Jena, 07743 Jena, Germany; \\ e-mails: ${ }^{1}$ eric_anton@web.de, ${ }^{2}$ b5bero@rz.uni-jena.de
}

Key words. Lepiceridae, head morphology, systematic position, function

\begin{abstract}
Adult head structures of Lepicerus inaequalis were examined in detail and interpreted functionally and phylogenetically. The monogeneric family clearly belongs to Myxophaga. A moveable process on the left mandible is an autapomorphy of the suborder. Even though Lepiceridae is the "basal" sistergroup of the remaining three myxophagan families, it is likely the group which has accumulated most autapomorphic features, e.g. tuberculate surface structure, internalised antennal insertion, and a specific entognathous condition. Adults of Lepiceridae and other myxophagan groups possess several features which are also present in larvae (e.g., premental papillae, semimembranous mandibular lobe). This is probably related to a very similar life style and has nothing to do with "desembryonisation". Lepiceridae and other myxophagans share a complex and, likely, derived character of the feeding apparatus with many polyphagan groups (e.g., Staphyliniformia). The mandibles are equipped with large molae and setal brushes. The latter interact with hairy processes or lobes of the epi- and hypopharynx. This supports a sistergroup relationship between both suborders.
\end{abstract}

\section{INTRODUCTION}

Lepicerus is a rather enigmatic and highly unusual genus of Coleoptera. It was pointed out by Sharp (1882) that the beetle "...shows no relationship of an evident character to any hitherto described Coleopterous families...", and affinities with Georissidae (Sharp, 1882), Dryopoidea (Blackwelder, 1944; Costa Lima, 1953), Cucujoidea (especially Trogossitidae; Sharp \& Muir, 1912), and Hydradephaga (Forbes, 1926) were discussed. Whereas the systematic position appears to be largely clarified today (e.g., Crowson, 1955; Reichardt, 1973; Beutel, 1999; see below), up to now very little is known about the biology and morphology (especially internal features), and the larvae are still unknown.

Lepicerus is the only genus of Lepiceridae (Reichardt, 1973, 1976) and is presently represented by two species. Together with Sphaeriusidae (= Microsporidae), Torridincolidae and Hydroscaphidae, Lepiceridae form the small coleopteran suborder Myxophaga, which is the sistergroup of the extremely species-rich Polyphaga according to Beutel \& Haas (2000), but the sistergroup of Adephaga according to Kukalová-Peck \& Lawrence (1993, 2004). Members of Lepiceridae can be very easily distinguished from all other known beetles by the fused tarsomeres with a single claw and the four-segmented, highly unusual antennae. Like all myxophagan beetles, Lepicerus spp. are small in size $(<2 \mathrm{~mm})$ and live in sandy substrates close to river edges (Navarrete-Heredia et al., 2005).

The genus is distributed from Mexico to northern South America. Most of the specimens were collected in moist environments at the edge of rivers (e.g., Reichardt, 1976), sometimes associated with filamentous algae, aquatic plants such as Ceratophyllum demersum, subaquatic grasses (Arce-Pérez \& Novelo-Gutiérrez, 1988), and in association with semiaquatic species [e.g., Georissus, Paracymus confusus Wooldridge, 1966, Anacaena debilis (Sharp, 1882)] and staphylinids (e.g., Homaeotarsus, Osorius, Diochus, Neobisnius, Xantholinus, Stenus and Coproporus) (Navarrete-Heredia et al., 2005). Previous statements about the presence of a plastron on the ventral side of the abdomen of Lepicerus bufo (Reichardt, 1976), which would suggest aquatic habits, have turned out as erroneous (Navarrete-Heredia et al., 2005; R.G. Beutel, pers. obs.). Both Lepicerus species were considered as very rare, but were collected in large numbers and on several occassions lately (R.E. Roughley, pers. comm.; Navarrete-Heredia et al., 2005).

Even though the proposed phylogenetic position of Lepiceridae as sistergroup to the remaining three myxophagan families (Beutel, 1999) appears plausible, important questions remained open (e.g., proximal segments of antennae, mandibular tooth, endoskeleton), and the entire morphology of these exceptional and enigmatic beetles is still very insufficiently known. A detailed description of the head appeared appropriate as several important functions are combined in this part of the body, and the phylogenetic value of characters of different parts of the head (e.g., antennae, mouthparts, sense organs, endoskeleton) is undisputed (see e.g., Anton \& Beutel, 2004).

The main purpose of this study is to provide detailed morphological information on external and internal head structures. A functional interpretation of some structural features is attempted based on the morphological data, and the characters are evaluated phylogenetically, in order to test the earlier proposed placement of the family. 


\section{MATERIAL AND METHODS}

\section{Taxa examined}

Myxophaga, Lepiceridae: Lepicerus inaequalis (Sharp, 1882) (5 specimens), Lepicerus bufo (Hinton, 1934) (3)

Hydroscaphidae: Hydroscapha natans LeConte, 1874 (5)

Microsporidae: Microsporus spp. (European and North American species; 3 and 6, respectively).

Torridincolidae: Ytu zeus Reichardt, 1973 (2), Iapir britskii (Reichardt \& Costa, 1967) (2), Delevea namibensis EndrödyYounga, 1997 (5), Torridincola rhodesica Steffan, 1964 (5), Satonius kurosawai (Sato, 1982) (20).

Specimens of Lepicerus inaequalis were stored in ethanol (70\%). Euparal was used as embedding medium for slide preparations of mouthparts and antennae. Parts of head capsules were macerated in $\mathrm{KOH}$ for skeletal preparations. Entire heads were embedded in Historesin and cut at $3 \mu \mathrm{m}$ with a Microm Microtome (HM 360) (cross section and longitudinal section). The sections were stained with methylene blue and acid fuchsine. SEM micrographs were made with an FEI (Philips) XL 30 ESEM TMP. Drawings were made with a camera lucida. The muscle terminology is based on v. Kéler (1963).

\section{MORPHOLOGY}

\section{Head capsule}

External structures (Figs 1-3). Head short and relatively broad (length $\sim 400 \mu \mathrm{m}$, width $\sim 500 \mu \mathrm{m}$ ), anteriorly bluntly rounded, due to protracted position of mentum (see below). Surface strongly uneven, rugulose. Mouthparts largely concealed. Labrum and mentum exposed, together forming a lid-mechanism enclosing the mandibles, maxillae and prementum. Protracted mentum kept in a nearly perpendicular position to clypeus, so anterior head appears snout-like in lateral view (Fig. 2). Short neck region posterior to compound eyes dorsally delimited by a transverse edge. Compound eyes strongly protruding, of hemisphaerical shape, placed on short, tubelike posterolaterally directed projections of the head capsule. Clypeus enlarged, dorsally bulging, with straight and anteriorly converging lateral margins. Frons raised above level of clypeus, with some small dorsal bulges, strongly uneven. Distinct frontoclypeal suture not recognisable due to deep transverse furrows between frons and clypeus, which enclose dorsal tubercles and reach lateral part of head capsule. Lateral part of frons forming duplicature around antennal insertion, covering scapus and pedicellus (proximal antennomeres concealed), with a narrow opening antero-mesad of compound eyes. Sides of head capsule with numerous irregular furrows, ridges and large tubercles, forming a relief for reception of antennae, anterior margin of prothorax and fore-legs. Occipital region around wide and roughly oval foramen occipitale very large, circular, distinctly separated from the rest of the head capsule by a sharp, nearly rectangular edge (Figs 2,3 ). Gula very short, transverse, strip-like, externally not distinctly separated from submentum. Laterally delimited by short, anteriorly converging gular carinae.

Internal skeletal structures (Figs 1, 19-26). Low gular carinae originating laterally from postoccipital ridge; enclosing posteroventral area of head capsule (gula); distinctly recognisable in cross sections as a
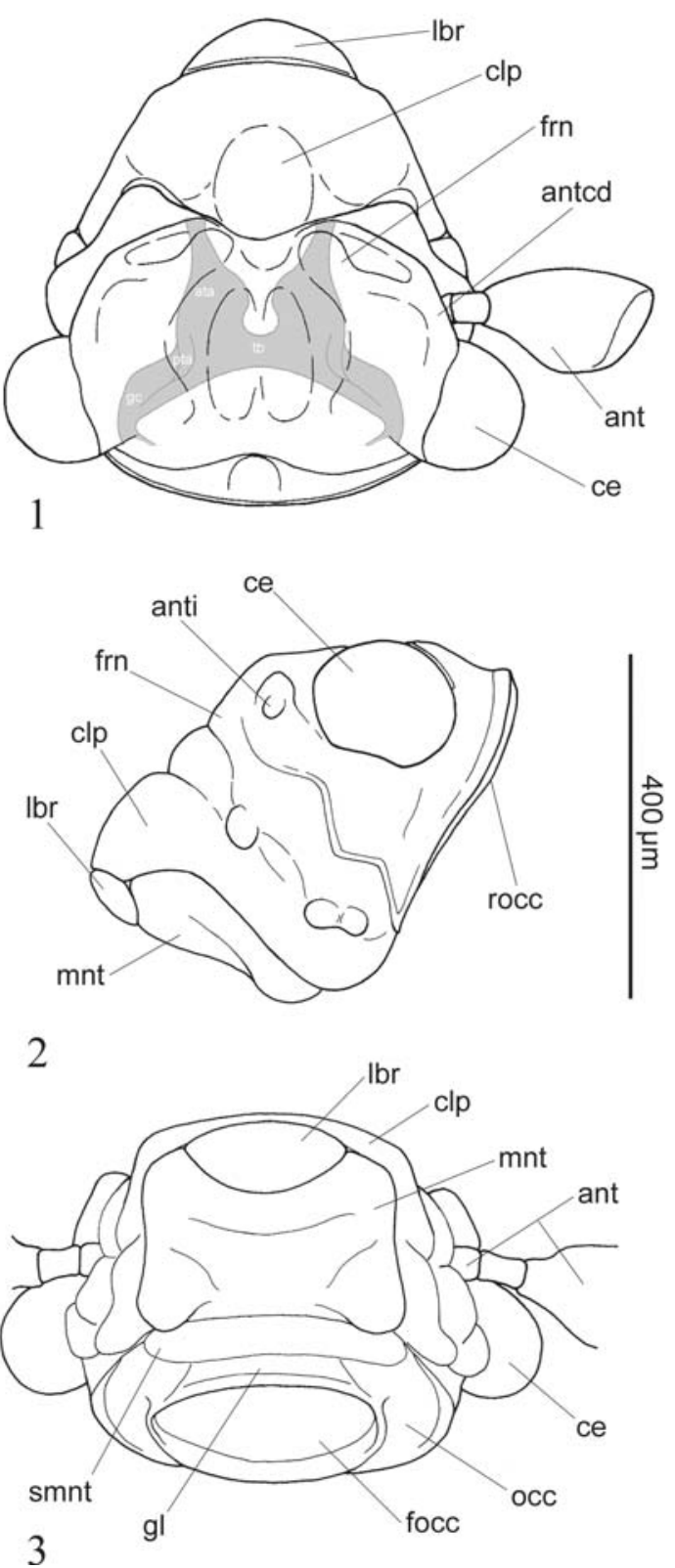

Figs 1-3. Head of Lepicerus inaequalis. 1 - dorsal view, left antenna removed, tentorium in grey; 2 - lateral view, antenna removed; 3 - ventral view. Abbreviations: ant - antenna, anti antennal insertion, antcd - dorsal part of antennal cavity, ata anterior tentorial arms, ce - compound eye, clp - clypeus, focc - foramen occipitale, frn - frons, gc - gular carina, gl - gula, lbr - labrum, mnt - mentum, occ - occiput, pta - posterior tentorial arms, rocc - occipital ridge, smnt - submentum, tb - tentorial bridge.

double-walled fold between gula and ventrolateral part of head capsule (Figs 23, 24); gular carinae distally continuous with posterior tentorial arms (PTA). PTA dorsally directed and converging towards midline, rod-like, connected by a plate-like horizontal tentorial body (Figs 1, 23, 26; TB [likely homologous with tentorial bridge as suggested by the origin of M42 and M52; see below]; laminatentorium apparently absent. Posterior part of TB tub-shaped in cross-section, bottom angles connected with PTA; lateral walls with apodemes for muscle inser- 

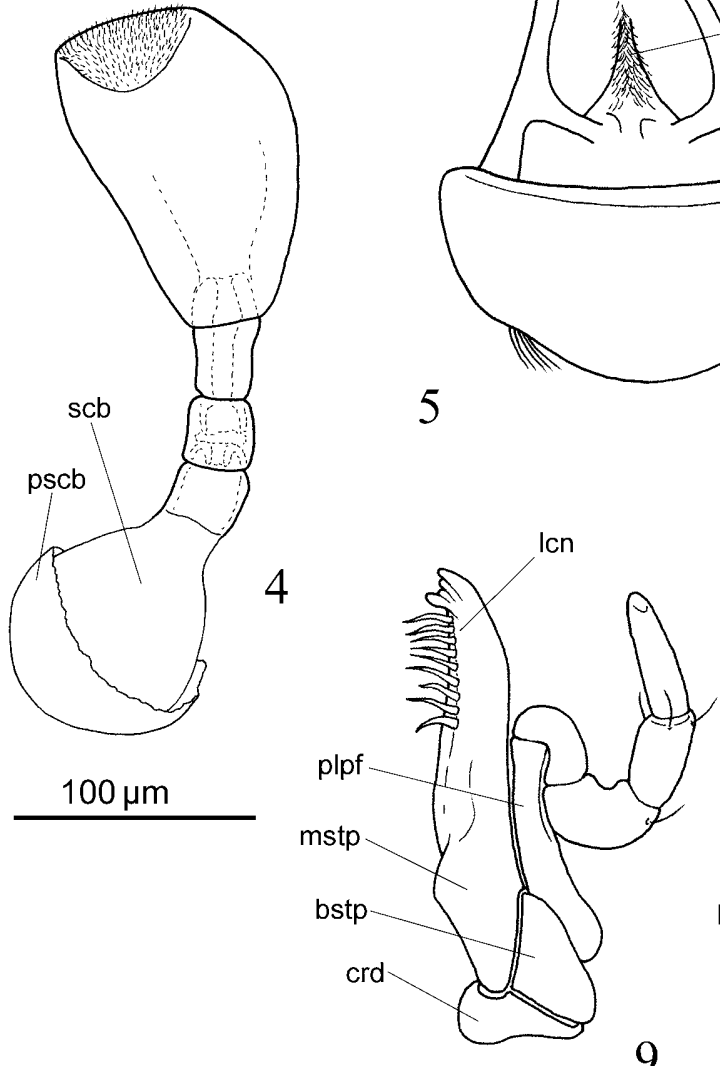

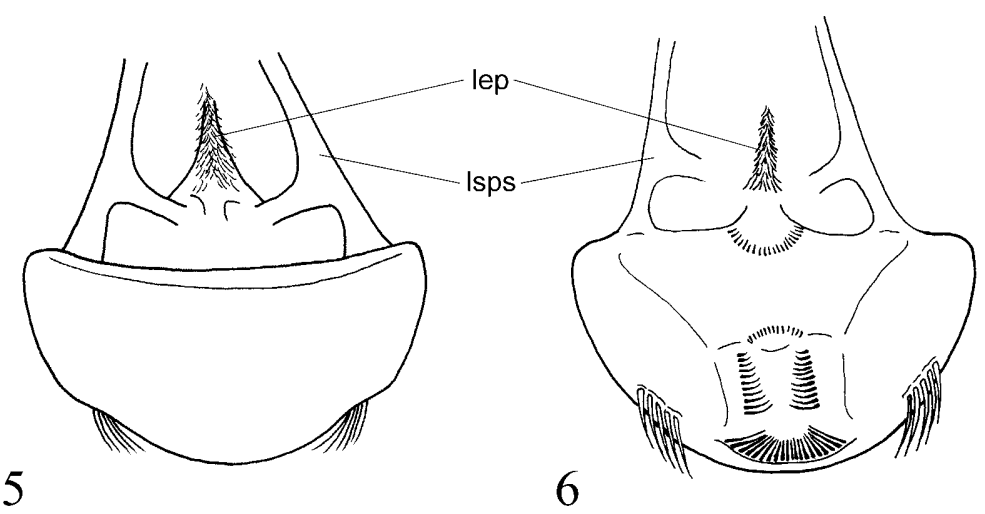

6

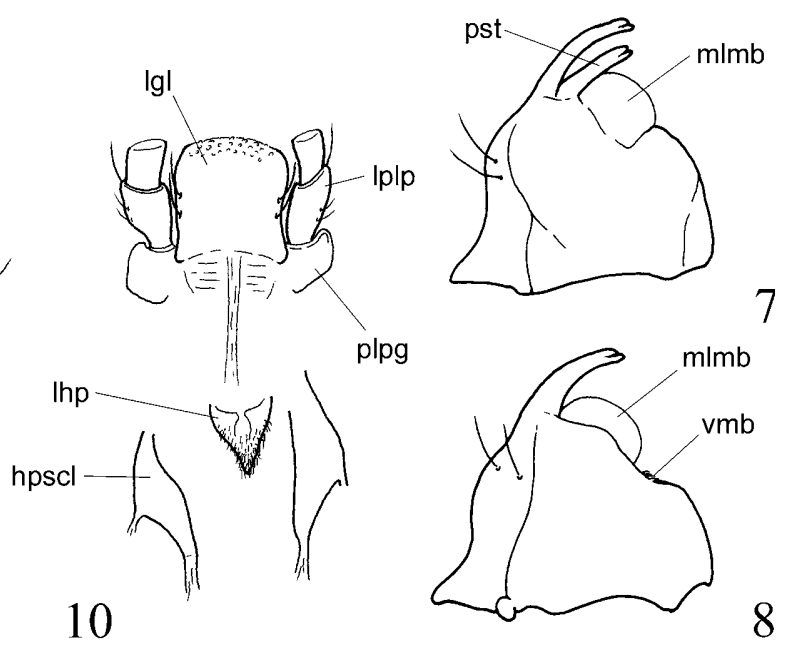

Figs 4-10. Lepicerus inaequalis, mouthparts (only distinctly sclerotised parts shown on drawings of epipharynx and hypopharynx). 4 - antenna, interrupted line shows internal connection of antennomeres; 5 - labrum and dorsal side of epipharynx, dorsal view; 6 - labrum and epipharynx, ventral view; 7 - left mandible, dorsal view; 8 - right mandible, ventral view; 9 - left maxilla, ventral view; 10 - prementum and hypopharynx, dorsal view. Abbreviations: bstp - basistipes, crd - cardo, hpscl - hypopharyngeal sclerite, lcn - lacinia, lep - longitudinal epipharyngeal process, lgl - ligula, lhp - longitudinal hypopharyngeal process, lplp labial palp, lsps - labral suspensorium, mlmb - median lobular mandibular brush, mstp - mediostipes, plpf - palpifer, plpg - palpiger, pscb - periscapal bulb, pst - prostheca, scb - scapal bulb, vmb - ventral mandibular brush.

tion; intermediate part flat and anterior part sinuate in cross-section. Anterior tentorial arms (ATA) originating from anterior TB (Fig. 22). ATA flat and plate-like, proximally almost adjacent, distally diverging and more rounded in cross-section (Figs 19-21). Dorsal tentorial arms not distinctly developed. ATA with an additional dorsal strut (possibly a reduced dorsal arm) close to its anterior origin at the posterolateral margin of the clypeus (anterior tentorial groove).

\section{Appendages}

Labrum (Figs 5, 6). Nearly semicircular, c. $2 \times$ broader than long. Dorsal surface strongly uneven, irregularly and coarsely punctured. Anterior margin smooth, without bristles, spines or sensilla. Lateral margin with rather indistinct sinuation with some frontomesally directed bristles. Labrum moveably attached to anterior clypeal margin by a hinge (Figs 16, 26), its outline fitting in a concavity of the anterior mentum, thus forming a lidmechanism. Ventral side of labrum largely smooth, but median line with anterior and posterior fields of microtrichia, followed posteriorly by densely setose longitudinal epipharyngeal process (LEP). Hind margin of labrum slightly concave, connected with a strongly developed, anteriorly forked suspensorium.

Musculature: M7 (absent); M9 (absent). Labrum without musculature, moved by M41 (see below).

Antenna (Figs 4, 11, 12, 20-24). 4-segmented, very short, with club-like distal antennomere; laterally directed. Insertion anterior to compound-eyes not visible externally, scapus fully enclosed in large cavity formed by frons (see above). Pedicellus and third antennomere partly concealed. Large distal antennomere exposed. Surface structure of sclerotised parts of antennomeres scalelike (Fig. 11). Proximal part of scapus spherical and enlarged ("scapal bulb"), reaching far into head capsule, very weakly sclerotised; surrounded by weakly sclerotised invagination ("periscapal bulb") of head capsule; distal part of scapus strongly sclerotised, forming a short and weakly curved cylinder. Scapus without condylus. Pedicellus cylindrical, almost appearing square in lateral view. Third antennomere slightly longer than pedicellus, slightly broadening distally. Terminal antennomere strongly enlargened, as long as all other antennomeres combined. Edges slightly diverging towards apex, with 


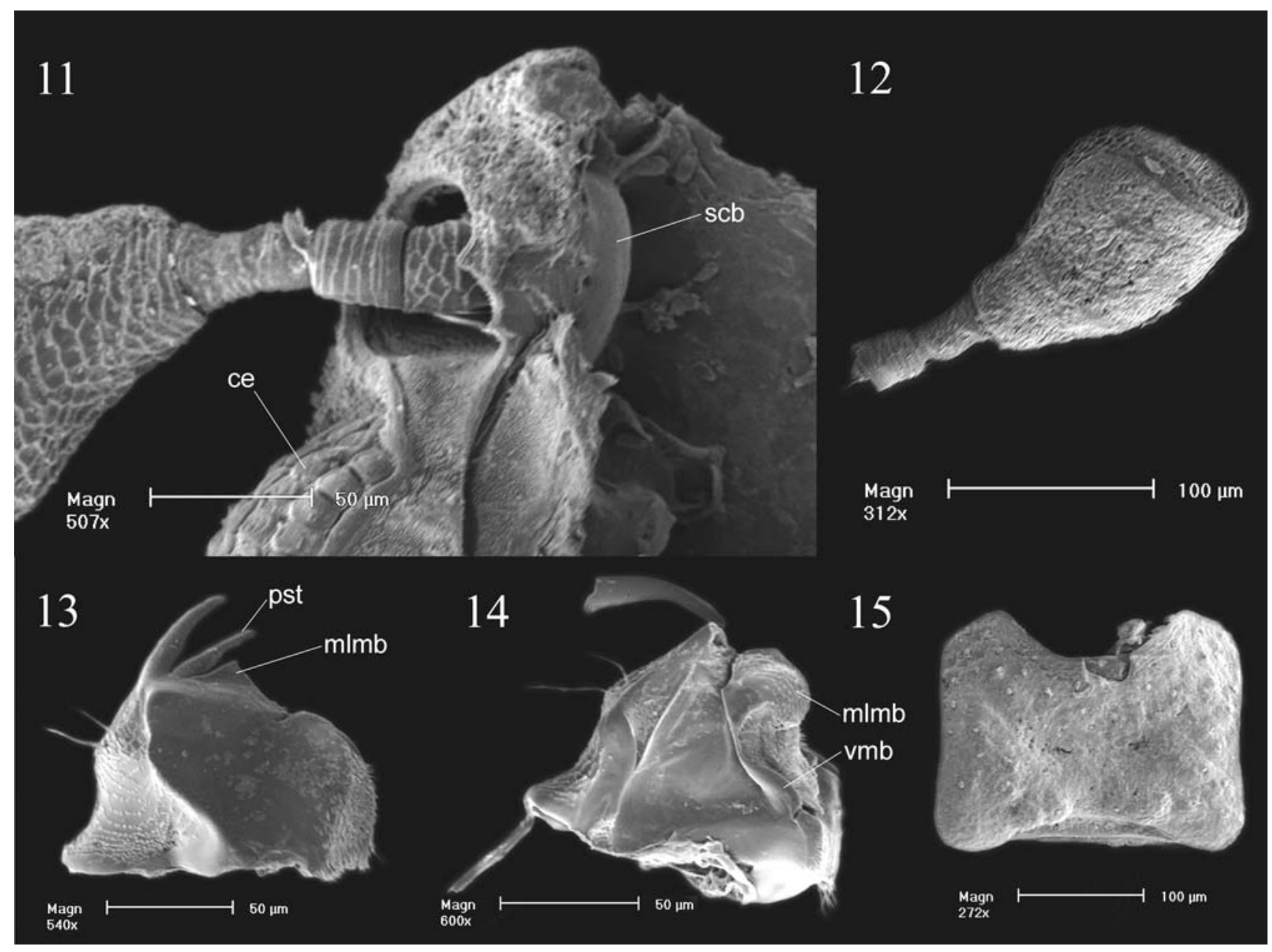

Figs 11-15. Lepicerus inaequalis, SEM. 11 - antenna and part of posterolateral head capsule, antennal insertion, ventral view; 12 - antenna, scapus removed; 13 - left mandible, dorsal view; 14 - right mandible, ventral view, mandibular apex missing; 15 - mentum, ventral view. Abbreviations: ce - compound eye, mlmb - median lobular mandibular brush, pst - prostheca, scb - scapal bulb, $\mathrm{vmb}$ - ventral mandibular brush.

anterior margin rounded and slightly convex and posterior margin slightly sinuate. Distal edge broadly incised, densely set with sensorial hairs. Base of antennomeres retracted into apical part of preceding segment; intraantennal movement strongly restricted (Fig. 4).

Musculature: M1 - M. tentorioscapalis anterior (Figs $21,22)$, origin $(=\mathrm{O})$ : dorsolateral surface of entire tentorial body and proximal half of ATA, very large, flat, triangular, insertion $(=\mathrm{I})$ : with short tendon antero-ventrally on scapal bulb, ventromesad of M2/M4; M2 - M. tentorioscapalis posterior (Figs 19-21), O: dorsolateral surface of distal half of ATA, anterad of M1, circular in cross-section, I: with short tendon antero-ventrally on scapal bulb, posterad of M1/M4; M4 - M. tentorioscapalis medialis (Figs 19-21, 26), O: near anterior tentorial groove, above M2, circular in cross-section, I: with short tendon anteroventrally on scapal bulb, dorsad of M1/M2; M5/M6 - M. scapopedicellaris lateralis/medialis (Fig. 23), O: proximal on semimembranous bulbiform part of scapus, I: base of pedicellus.

Mandible (Figs 7, 8, 13, 14, 18). Approximately triangular in dorsal view. Lateral side of mandible broad near the base, narrowing towards the apex; lateral surface with rows of short hairs and with two anterolaterally directed long setae. Anterior edge regularly rounded. Distal part forming a long and slender (length : width $\sim 10: 1$ ), parallel-sided process with a bidentate apex. Moveable prostheca (Figs 7, 13) present only on left mandible, inserted close to apical process; long and thin (length : width $\sim 1: 7$ ), parallel-sided and straight. Mesal mandibular margin between slender distal part and mola with semicircular semimembranous lobe with smooth margin ("mesal lobular mandibular brush", mlmb, Figs 7, 8, 14). Smaller semimembranous structure densely set with hairs present posterior to this lobe, on ventromesal mandibular margin ("ventral mandibular brush", vmb, Figs 14, 18). Molae strongly asymmetric; left mola very large and convex, occupying c. 1/2 of mesal mandibular edge; right mola convex, smaller, occupying c. 1/3 of mesal edge; posterior margin of molae with attachment area of adductor tendon; hind margin densely set with microtrichia.

Musculature: M11 - M. craniomandibularis internus (Figs 20-25), O: lateral head capsule from posterior edge of compound eyes to level of posterior clypeus (M11 pars verticalis) and ventral part of posterior head capsule (M11 
16
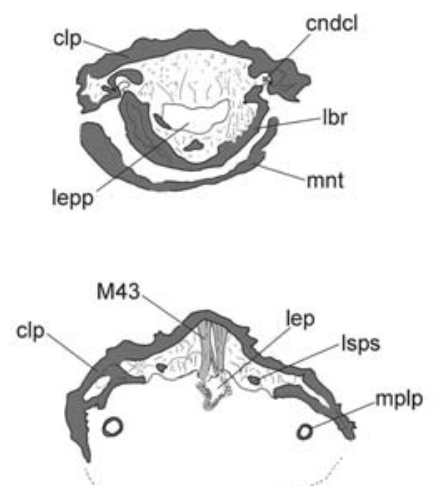

17

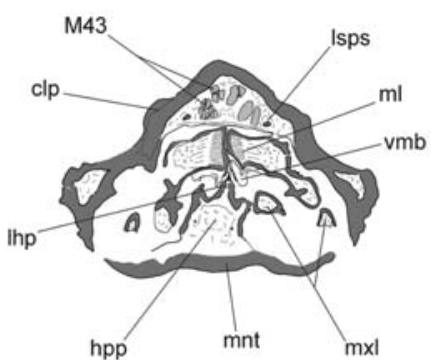

18

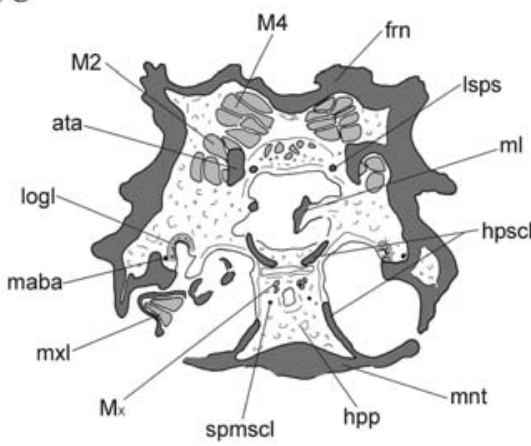

19

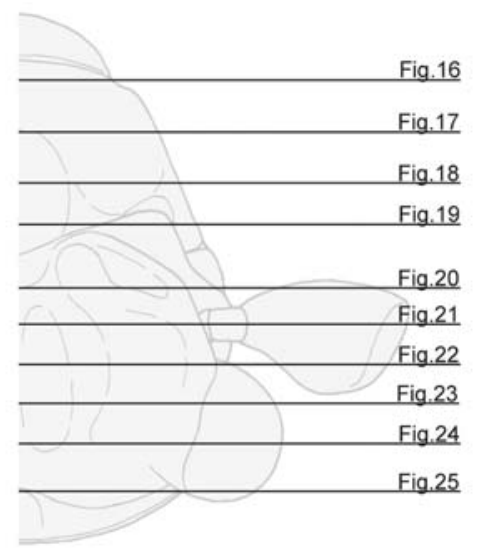

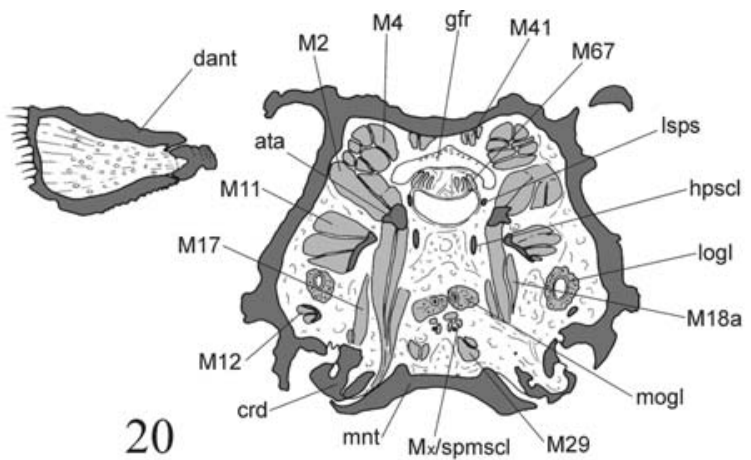
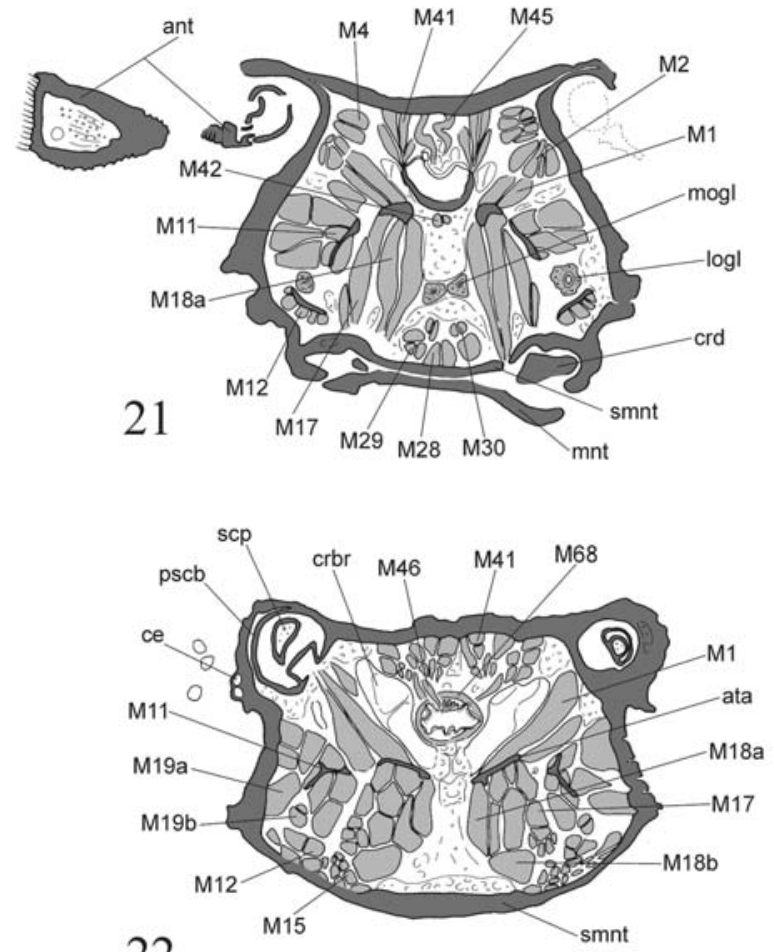

22

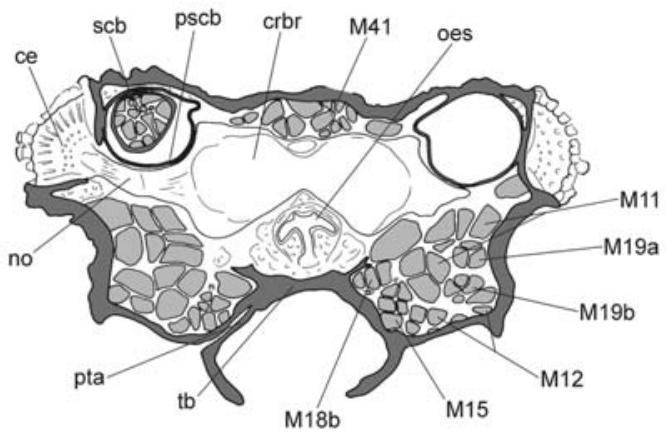

23

Figs 16-23. Head of Lepicerus inaequalis, cross-sections (musculature/glands in lighter grey, sclerotised parts in darker grey; image of head on lower left side shows the planes of sections for Figs 16-25). 16 - labral region; 17 - epipharyngeal region; 18 level of molae/hypopharynx; 19 - posterior preoral cavity; 20 - level of anterior frons; 21 - level of anatomical mouth opening; 22 anterior cerebral region; 23 - level of anterior part of compound eyes and scapal bulb. Abbreviations: ant - antenna, ata - anterior tentorial arms, ce - compound eye, clp - clypeus, cndcl - labro-clypeal condylus, crbr - cerebrum, crd - cardo, dant - distal antennomere, frn - frons, gfr - ganglion frontale, hpp - hypopharynx, hpscl - hypopharyngeal sclerite, lbr - labrum, lep - longitudinal epipharyngeal process, lepp - epipharyngeal lumen, lhp - longitudinal hypopharyngeal process, logl - lateral oral gland, lsps labral suspensorium, M1-67/Mx - musculature, maba - mandibular abductor apodeme, $\mathrm{ml}$ - mola, mnt - mentum, mogl - median oral gland, mplp - maxillary palp, mxl - maxilla, no - optic nerve, oes - oesophagus, pscb - periscapal bulb, pta - posterior tentorial arms, scb - scapal bulb, scp - scapus, smnt - submentum, spmscl - strutlike premental sclerite, tb - tentorial bridge, vmb - ventral mandibular brush. 


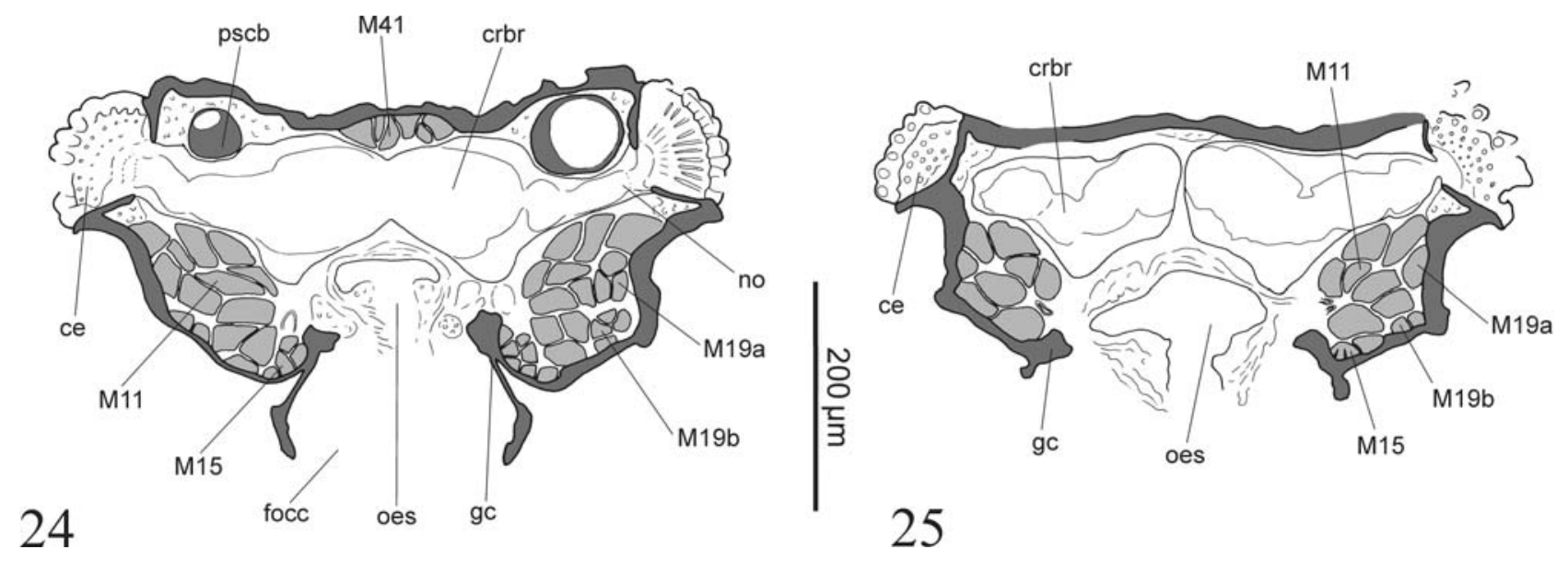

Figs 24-25. Head of Lepicerus inaequalis, cross-sections (musculature/glands in lighter grey, sclerotised parts in darker grey). 24 - level of central part of compound eyes and posterior periscapal bulb; 25 - posterior head region. Abbreviations: ce - compound eye, crbr - cerebrum, focc - foramen occipitale, gc - gular carina, M1-M41 - musculature, no - optic nerve, oes - oesophagus, pscb - periscapal bulb.

pars genalis); both parts forming an almost right angle in cross-section, enclosing the lateral parts of the extrinsic maxillary musculature (see below), I: apodeme attached with short tendon on posteromedian edge of molar part of mandible; M12 - M. craniomandibularis externus (Figs 19-23), O: ventrolateral part of head capsule; very small and flat, located distinctly below M11; I: on ventral side of a plate-like apodeme; long, thin tendon connects apodeme with external edge of mandibular base close to the ventrolateral wall of the head capsule (Fig. 19, maba).

Maxilla (Figs 9, 18-21). Cardo large, trapezoid. Basistipes small, of triangular shape. Mediostipes long and slender, not distinctly separated from mesally adjacent lacinia. Lacinia also long and slender, conically narrowed towards apex; inner margin with row of long, anteriorly thickening bristles; distal part with several strong spines; apex forming a hook. Galea apparently absent (undivided "mala"; Beutel, 1999). Palpifer inserted on dorsal side of maxilla, opposed to mediostipes and lacinia; laterodistal margin with group of bristles; insertion of palp distal. Palpomere I c. $3 \times$ longer than broad, strongly bent outwards (c. $\left.90^{\circ}\right)$; palpomere II thicker than palpomere I and slightly longer, bent in the opposite direction (c. $90^{\circ}$ ); palpomere III conical, more slender than palpomere II, c. $1.5 \mathrm{x}$ longer than broad; distal palpomere IV as slender as palpomere I and slightly longer than preceding segment, slightly conical, with blunt apex.

Musculature: M15 - M. craniocardinalis externus (Figs 22-25), O: posterior head capsule, between foramen occiptale and gular carinae; I: on a dorsally directed process at the cardo base; M17 - M. tentoriocardinalis (Figs 20-22), O: entire ventrolateral surface of tentorial body and almost entire ventrolateral surface of ATA; very close to M18a; I: on posteromedian process of cardo; M18 - M. tentoriostipitalis, composed of two subcomponents; M18a (Figs 20-22, 26): mesad to M17, almost vertical, $\mathrm{O}$ : ventromesal surface of $\mathrm{TB}$ and ventromesal surface of ATA, I: with a tendon on stipital base; M18b (Figs 22, 23): O: lateral posterior tentorial arm, below tentorial bridge, moving along ventral head capsule, I: with a tendon together with M18a; M19 - M. craniolacinialis: composed of two subcomponents, enclosed by M11 (mesally) and M12 (ventrally); M19a (Figs 22-25): $\mathrm{O}$ : posterolateral part of head capsule, mesally adjacent with M11; I: attached to the base of the lacinia by means of a tendon; M19b (Figs 22-25): O: ventrolateral part of head capsule, below M19a, enclosed between M11 and M12; I: same insertion as M19a; M20 - M. stipitolacinialis: not identified; M21 - M. stipitogalealis: not identified; M22/M23 - M. stipitopalpalis externus/internus (Fig. 19), both muscles form a single bundle, O: stipes, I: base of maxillary palp; M25 - M. palpopalpalis secundus: O: lateral wall of palpomere II, I: basal margin of palpomere III; M26 - M. palpopalpalis tertius: not identified, probably absent.

Labium (Figs 2, 3, 10, 15-22, 26). Submentum not recognisable as a separate external sclerite; represented by an internal transverse ridge (visible on cross and longitudinal sections, origin of Mm 28-30, Fig. 26) between the mentum and gula. Mentum large, plate-like, movably connected with head capsule (Fig. 26; on anterior gular margin, see above); approximately rectangular, hind margin and lateral margins slightly concave. All corners rounded; anterior margin with concavity fitting with anterior labral margin. Prementum strongly reduced, semimembranous, not visible externally; ligula between palps large, rectangular, slightly longer than wide, with rounded anterolateral edges; anteriorly semimembranous, densely set with small papillae; palpiger also semimembranous. Palp 2-segmented, sclerotised; palpomere I stout, longer than wide, with slightly convex outer margin; palpomere II nearly quadrangular in lateral view, with blunt and semimembanous apex. Several long setae insert laterally on the ligula and palpomeres.

Musculature: M28 - M. submentopraementalis (Figs 21, 26): unpaired, short, very close to dorsal surface of mentum, O: together with M29 and M30 on frontal side of a transverse submental carina, I: with long thin tendon 
on a fold between mentum and prementum; M29 - M. tentoriopraementalis inferior (Figs 20, 21, 26), paired, close to lateral walls of hypopharynx, $\mathrm{O}$ : on submental carina, laterad of M28, I: not clearly identified, probably laterally on prementum; M30 - M. tentoriopraementalis superior (Figs 21, 26), O: paired, beside M28, dorsad of M29, muscle rather short, I: each of both muscle-bundles connected on thickened posterior end of a long strut-like premental sclerite (Fig. 26, "spmscl", sclerite with own musculature, see below); M36 - M. palpopalpalis secundus: not identified, probably absent.

Two additional muscles with unknown homology are associated with the labio-hypopharyngeal complex. The first muscle (Mx, Figs 19, 20, 26) originates on the posterior end of the strut-like premental sclerite, anterior to the insertion of M30. The precise point of insertion could not be clarified. It is possibly homologous with M33 (M. praementopalpalis internus). The second muscle (Mxx, Fig. 26) originates ventrally on the plate-like sclerite connecting the median oral glands (see below). The muscle is short and splits into two subunits, which insert dorsally on the thickened posterior end of the strut-like premental sclerite, laterad of the insertion of M30 and the origin of Mx (Fig. 26).

\section{Digestive tract}

Epipharynx (Figs 6, 17, 26). Paired sclerite ("labral suspensorium", lsps, Figs 17-21) and median longitudinal epipharyngeal bulge or process (LEP, Figs 17, 26) posteriorly adjacent to ventral side of labrum. Suspensorium rod-like, anteriorly forked; apices form insertion point of M41; functioning as labral closing-mechanism. LEP well developed, densely set with hairs, posteriorly tapering, rectangular in cross-section; situated anterior to molae, between semimembranous mesal lobular mandibular brushes (see above).

Musculature: M43 - M. clypeopalatalis (Figs 17, 18, 26): several thin and short bundles, O: medially and paramedially on anterior clypeus, I: paramedian bundles slightly converging towards insertion, laterally attached to dorsal prepharyngeal wall; median bundles parallel, inserting at posterior base of longitudinal epipharyngeal process.

Hypopharynx (Figs 10, 18, 19, 26). Dorsal side with small longitudinal hypopharyngeal process (LHP, Figs 18, 26). LHP densely set with trichia, much smaller than LEP, supported by a triangular sclerite. LHP situated opposite to molae, between semimembranous ventral mandibular brushes (Fig. 18, see above). Hypopharynx in cross-section rectangular, nearly quadrate; lateral sides strongly reinforced by a sclerite; lateral sclerites medially not fused, posteriorly reaching insertion point of M41, thus forming a connection with the labral suspensorium.

Musculature: M41 - M. frontohypopharyngalis ("retractor angulum oris"; Snodgrass 1935) (Figs 20-24, 26), subdivided into four subunits; posterior part divided into lateral subunits and a large median part by M46 (see below); median part further divided into two subunits anteriorly, O: frons, I: median and lateral parts attached to posterolateral hypopharyngeal apodeme and epipharyn-

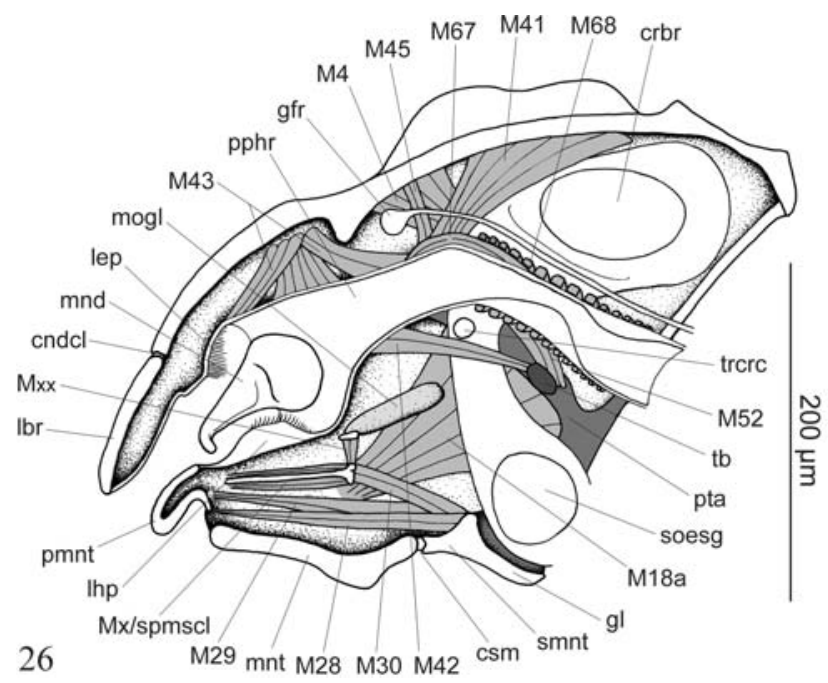

Fig. 26. Head of Lepicerus inaequalis, sagittal section (musculature/glands in lighter grey, tentorium in darker grey). Abbreviations: cndcl - labro-clypeal condylus, crbr - cerebrum, $\mathrm{csm}$ - submento-mental condylus, gfr - ganglion frontale, gl gula, lbr - labrum, lep - longitudinal epipharyngeal process, lhp - longitudinal hypopharyngeal process, M4-M68/Mx/Mxx musculature, mnd - mandible, mnt - mentum, mogl - median oral gland, pmnt - prementum, pphr - prepharyngeal lumen, pta - posterior tentorial arm, smnt - submentum, soesg - suboesophageal ganglion, spmscl - strutlike premental sclerite, tb - tentorial bridge, trerc - tritocerebral commissure.

geal apodeme by means of a short tendon (Fig. 21); M42 - M. tentoriohypopharyngalis: (Figs 21, 26), O: with a tendon from the anteromedian edge of the tentorial body, I: sclerotised area on ventral side of prepharynx.

Pharynx and oesophagus (Figs 22-25, 26). Relatively narrow, semicircular in cross section, with well developed transverse musculature. Oesophagus narrow, slightly folded, surrounded by a thin layer of ring musculature.

Musculature: M45 - M. frontobuccalis anterior (Figs 21, 26): O: paramedially on anterior frons, anteromesad of M41, I: dorsally on anatomical month; M46 - M. frontobuccalis posterior (Fig. 22): O: frons, between attachment areas of M41, thus splitting M41 into a mesal and lateral component, converging towards insertion, closely adjacent with anterior surface of cerebrum, I: dorsolaterally on pharynx; M50 - absent; M51 - absent; M52 - M. tentoriopharyngalis (Fig. 26): O: posterodorsal TB postero-mesad to origin of M1, relatively short, anteriorly directed, I: ventral pharyngeal wall; M67 - M. transversalis buccae (Figs 20, 26): several transverse muscle bundles; M68 - M. anularis stomodaei (Figs 22, 26): ring musculature, posterior to M67; M69 - M. longitudinalis stomodaei: layer of longitudinal muscles, covered by M68.

Cerebrum and suboesophageal ganglion (Figs 20, 23-26). Cerebrum large in relation to head size; central part on level with compound eyes; dorsally limited by pharyngeal musculature (M41/45/46) and laterally by antennal muscles and scapal bulb; posterior cerebrum adjacent with postoccipital ridge. Optic nerve passing 

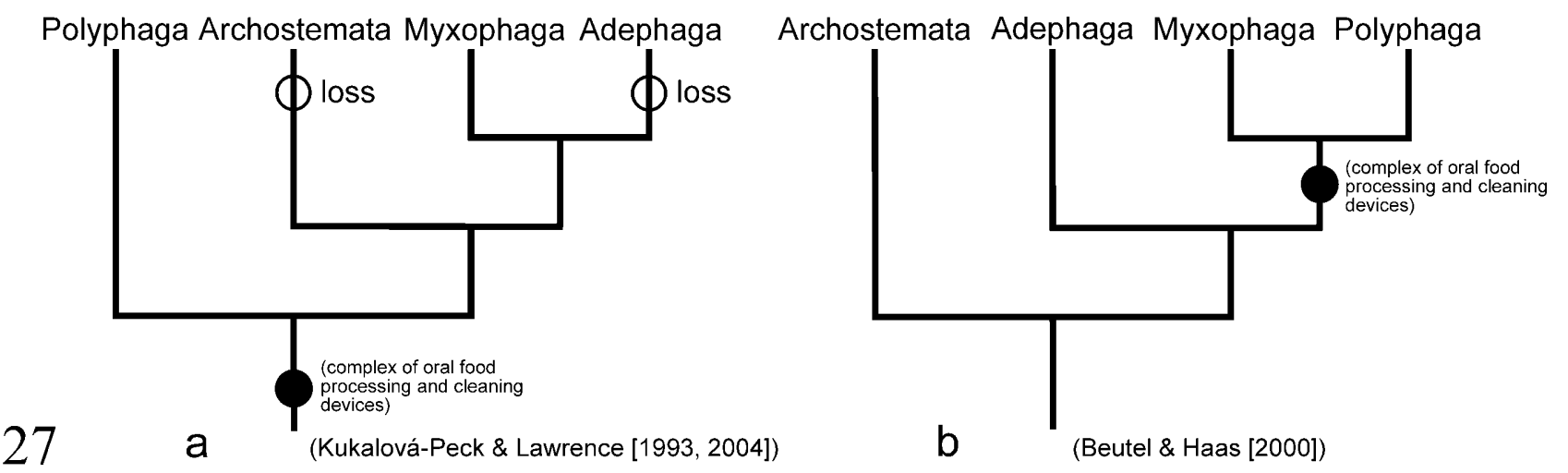

Fig. 27. Two hypotheses about the relationships of the four coleopteran suborders. a - [after Kukalová-Peck \& Lawrence (1993, 2004)] this branching pattern suggests that the complex oral food processing and cleaning devices (mandibular molae, mesal mandibular brushes, longitudinal epipharyngeal process, longitudinal hypopharyngeal process) belong to the groundplan of Coleoptera, and were secondarily lost twice in Adephaga and Archostemata (further losses within Polyphaga); b - [after Beutel \& Haas (2000); Crowson (1955)] the complex feeding apparatus originated once in the stem-lineage of a Myxophaga + Polyphaga clade (with secondary modifications in some polyphagan groups [e.g. Staphylininae, Curculionoidea]).

ventral side of scapal bulb. Antennal nerve thin, originating from deutocerebrum, reaching scapus through a small, mesal opening of scapal bulb. Frontal ganglion large, situated above prepharynx (Figs 20, 26). Frontal connectives thick, laterally enclosing prepharynx. Suboesophageal ganglion large in relation to head size, occupying the entire space between gula, gular carinae/PTA and tentorial body.

Glands (Figs 19-21, 26). Head capsule with two pairs of large tubular glands. Glands circular in cross-section; cell layer simple, surrounding sclerotised glandular duct. First pair of glands (lateral oral glands) positioned between M11 and M12; glandular duct strongly widening anteriorly, glands thus appearing cone-shaped; open into preoral cavity dorsad of maxillae at the level of the stipes. Second pair of glands (median oral glands) constant in diameter, positioned close to each other and above labial musculature (M28-M30); posterior margin in front of suboesophageal ganglion; open into preoral cavity in a fold of the posteriormost dorsal hypopharynx, ventrad of the posterior molae. Both glandular ducts connected with each other by sclerotised plate (Fig. 26) posterad of gland opening; plate anteriorly connected with hypopharyngeal sclerite; musculature attached to plate (Mxx, see above) possibly responsible for release of secretions.

\section{Functional interpretations}

Among other autapomorphies (see below), Lepicerus is characterised by two unusual and complex characters, a specific entognathous condition and a strongly modified antenna and antennal insertion. The mandibles, maxillae and the prementum are completely or almost completely enclosed in a preoral chamber formed by the mentum, labrum, clypeus and the genae. The labrum and mentum are moveably connected with the clypeus and submentum, respectively, and form a lid-like closing mechanism. No muscles are directly attached to the mentum. Nevertheless, it can be lifted by contraction of the premental muscles (M. submentopraementalis and $\mathrm{Mm}$. tentoriopraementales, M28-30) and, indirectly, by con- traction of M. frontohypopharyngalis (see below). Closing the opening of the functional mouth is apparently mainly achieved by the labrum. Its posterior edges are connected with the head capsule by a hinge (Figs 16, 26; "cndcl"). The labral retractor M. frontoepipharyngalis (M9) is absent. The labrum is moved by contraction of the strongly developed M. frontohypopharyngalis (M41). The apices of the long and thin processes of the labral suspensorium serve as attachment area for this muscle (= "M. retractor angulum oris"; Snodgrass, 1935). Posterior extensions of the hypopharyngeal sclerite, which is firmly joined with the mentum, are directly connected with the posterior labral suspensorium (Figs 20, 21; lsps, hpscl) and also serve as attachment area of M41. Therefore, in addition to its usual function, i.e. the elevation of the hypopharynx and opening of the anatomical mouth ("mouth angles"), M41 serves as flexor of the labrum (and, indirectly, of the mentum to a minor degree), together with the hinge at the labral base. Closing the functional mouth is mainly caused by muscle contraction, whereas the opening is mainly achieved by the elasticity of the associated sclerotised and semimembranous structures.

The enclosed mouthparts are relatively small, but otherwise fully developed except for the loss of the galea. The preferred food and feeding behaviour of Lepicerus is unknown, but is is likely that they largely rely on algae as do other myxophagans and Hydraenidae, which live in similar habitats. As in other groups with weakly developed mandibular apices (Hydraenidae, Ptiliidae; Betz et al., 2003), the strongly sclerotised and toothed lacinia is used to collect food, whereas the mechanical processing takes place between the mandibular molae (see also Beutel et al., 2001).

A condition not described for any other group of beetles is the antennal articulation, which is deeply sunk into a socket formed by the frontal parts of the head capsule. In addition to the unusually large cavity enclosing the large and unsclerotised base of the scapus ("periscapal 
bulb"), the duplicature of the frons encloses also the first three antennomeres. It is somewhat surprising that the extrinsic antennal musculature (M1/2/4) is very strongly developed despite of the limited movability and the shortness of the antenna as a whole. The reduced number of antennomeres and the shape of these segments strongly suggest that the intraantennal movability is also restricted. Nevertheless, Mm. scapopedicellares anterior and posterior (M5/6) are very large. The functional background of these transformations is rather unclear and interpretations remain speculative as long as direct observations are not available. What can be said with reasonable certainty, however, is that the main movement carried out by the antenna is retraction into the socket from a position with the apical part resting in the prothoracic antennal groove. Shortened antennae with prothoracic antennal grooves are also present in Hydraenidae and Hydrophiloidea. However, the antennae of most adults of these taxa have a specialised function as accessory breathing organs, which can be ruled out for Lepiceridae. A dense field of hairs along the distal edge of the large apical antennomere has probably a sensorial function, but is certainly unsuitable for holding an air film, as it is the case in most hydraenids and hydrophiloids. It cannot be excluded that the antennal modifications are related to burrowing in substrate, but a similar condition is not found in Sphaeriusidae, which live in similar conditions, and the antennae are largely unmodified in other adult beetles with burrowing habits such as Omophron or Clivinia (Carabidae).

\section{DISCUSSION}

Adult myxophagan beetles share two presumptive apomorphies of the head. A moveable "prostheca" is present on the left mandible. This character was verified for Lepiceridae for the first time in the present study. The galea is completely reduced or fused with the lacinia. The former interpretation appears more likely, as the "mala" of Lepiceridae does not show any structural differences to the lacinia of other beetles. Another common feature of myxophagan adults (and larvae) is a tendency towards entognathism (see Beutel \& Haas, 1998: larvae). The mandibles and the distal parts of the maxillae are enclosed to a varying degree in a working chamber between the mentum and labrum. The highest degree of closure of the preoral cavity is reached in adults of Lepiceridae. This tendency is likely related to small size and microphagous habits. Similar conditions occur in small sized polyphagans, e.g., in Ptiliidae. Another trend in Myxophaga goes towards the reduction of the number of antennomeres. However, this has taken place several times independently, and the basal coleopteran condition of 11 antennomeres (Coleoptera s. str.; see Beutel, 1997) belongs to the groundplan of Myxophaga (Sphaeriusidae). Nine antennomeres are present in Torridincolidae, eight or five in Hydroscaphidae, and only four in Lepiceridae (Reichardt, 1973).

Lepiceridae were placed as sister-group of the remaining myxophagan families in Beutel (1999). As the larvae of Lepicerus are unknown, this hypothesis is based only on adult synapomorpies of Torridincolidae, Hydroscaphidae and Sphaeriusidae, i.e. the small, peglike apical maxillary palpomere, the complete fringe of hairs at the hind wing margin, a distinctly curved subcosta which is connected with the radius anterior after a short distance, and the absence of the transverse ridge of the metaventrite (Beutel, 1999). New synapomorphic characters of Myxophaga excluding Lepiceridae were not discovered during this study, but neither characters which would suggest an alternative placement of the group.

Despite the position of Lepiceridae as "basal" sistergroup of the remaining Myxophaga, they are probably the "most derived family", i.e. the group which has accumulated the highest number of autapomorphies. Lepiceridae are characterised by several unusual characters of the head such as the ventral orientation of the mouthparts, the four-segmented, clubbed antennae with a unique type of insertion, the specific entognathous condition (see above) and the strongly sculptured surface of the dorsal side. However, there are also unusual autapomorphic features of other body parts such as the pronotal antennal groove, the fused tarsomeres, the presence of elytral grooves for reception of the middle and hind legs, and the strongly sculptured surface of the pronotum and elytra. Besides the specific habitat and feeding-habits it appears plausible that at least some of these apomorphies are related to specific defense mechanisms. The body of Lepiceridae adults is not only camouflaged with substrate particles, but the strongly sclerotised beetles are obvioulsly able to assume a compact defensive position with retracted antennae, mouthparts and legs. This makes them very inconspicuous and unattractive for potential predators. Some features resemble morphological specialisations of paussine beetles (e.g., enlarged labium, large and compact antennal club formed by fused flagellomeres; see Darlington, 1950: p. 64; Nagel, 1979). However, to assume that Lepiceridae are myrmecophilous at least in one stage of their life would be speculative at the present stage of knowledge, and this is apparently not the case in adults (Navarrete-Heredia et al., 2005).

It is interesting that, in contrast to other groups of beetles (or Endopterygota), adults of myxophagan groups show some characteristic features which do also occur in larvae: semientognathous mouthparts, the presence of a semimembranous mandibular lobe, the absence of the galea, and the presence of ligular papillae. It is plausible to assume that this is due to very similar microhabitats and feeding habits in the larval and adult stages. To consider myxophagan larvae as "desembryonized" (like polyphagan larvae) as suggested by Kirejtshuk (1991) would be misleading. Larvae of Myxophaga show the typical features of immature holometabolous insects such as e.g., the absence of a sclerotised gula, an antenna with few segments, short legs without subdivided tarsi, and a structurally simple condition of the thorax and abdomen.

A sistergroup relationship between Myxophaga and Polyphaga was postulated by Beutel \& Haas (2000) based on a cladistic analysis of a broad set of morphological caracters of larvae and adults, in contrast to Kukalová- 
Peck \& Lawrence (1993, 2004), who proposed a sistergroup relationship between Myxophaga and Adephaga based on characters of the hind wing. The former hypothesis, especially the sistergroup relationship between Myxophaga and Polyphaga, seems to be supported by features of the head of adults (Fig. 31). The feeding apparatus of adult myxophagans and many polyphagan groups (e.g., Hydrophiloidea, Hydraenidae, Leiodidae; Anton \& Beutel, 2004; Lathridiidae, Phalacridae, etc., Anton, pers. obs.) are complex and structurally very similar. The mandibles are equipped with large, asymmetric molae and brush-like structures on the inner surface (Anton \& Beutel, 2004). These brushes interact with a hairy median lobe or process of the epipharynx, and a similar lobe of the hypopharynx. This condition is probably correlated with microphagous feeding habits (algae, hyphae or spores of fungi; e.g., Leschen, 1993; Hansen, 1997). A mola and the specific brushes are absent in Archostemata (Hörnschemeyer et al., 2002) and also in the groundplan of Adephaga (Acorn \& Ball, 1991), even though different brush-like structures have evolved within Carabidae and other adephagan groups (e.g., Noteridae). That this is a plesiomorphic condition within Coleoptera is suggested by the fact that molae and brushes are also missing in adults of potentially related groups such as Neuropterida (e.g., Röber, 1942) or Strepsiptera (e.g., Protoxenos; Pohl et al., 2005; Beutel \& Pohl, 2004). A sistergroup relationship between Polyphaga and the remaining Coleoptera as suggested by Kukalová-Peck \& Lawrence (1993, 2004) would imply that this type of feeding apparatus has evolved once (groundplan of Coleoptera) and was lost twice (Archostemata, Adephaga) (Fig. 31), or has evolved two times independently, which appears rather unlikely considering the complexity of the involved structures. The alternative hypothesis proposed by Crowson (1955) suggests that this condition has evolved once in the myxophaganpolyphagan lineage. Both hypotheses require the additional assumption that other types of feeding apparatuses have evolved several times within Polyphaga in correlation with carnivorous or specialised phytophagous feeding habits.

ACKNOWLEDGEMENTS. We are greatly indebted to R.E. Roughley (University of Manitoba), A. Short (Cornell University) and to C. Costa (Museo de Zoologia, São Paulo) for the gift of valuable specimens. Valuable information and specimens of both lepicerid species were provided by J.L. NavarreteHeredia (Universidad de Guadalajara, Mexico). This is also gratefully acknowledged. We are also grateful to V.V. Grebennikov for carefully reading and correcting the manuscript.

\section{REFERENCES}

ACoRn J.H. \& BALL G.E. 1991: The mandibles of some adult ground beetles: structure, function, and the evolution of herbivory (Coleoptera: Carabidae). Can. J. Zool. 63: 638-650.

Anton E. \& Beutel R.G. 2004: On the head morphology and systematic position of Helophorus (Coleoptera: Hydrophiloidea: Helophoridae). Zool. Anz. 242: 313-346.

Arce-Pérez R. \& Novelo-Gutiérrez R. 1988: Primer registro de Lepicerus bufo (Hinton, 1934) (Coleoptera: Lepiceridae) para el estado de Morelos, México. Folia Entomol. Mex. 75: $156-158$.

Arce-Pérez R., Navarrete-Heredia J.L. \& Beutel R.G. 2005: 6.1. Lepiceridae Hinton, 1936 (= Cyathoceridae). In Beutel R.G. \& Leschen R.A.B. (eds): Handbook of Zoology, Volume IV Arthropoda: Insecta. Coleoptera, Vol. 1: Morphology and Systematics (Archostemata, Adephaga, Myxophaga, Polyphaga partim). Walter De Gruyter, Berlin, New York, p. 45.

Betz O., Thayer M.K \& Newton A.F. 2003: Comparative morphology and evolutionary pathways of the mouthparts in spore-feeding Staphylinoidea (Coleoptera). Zool. Scr. 84: 179-238.

Beutel R.G. 1997: Über Phylogenese und Evolution der Coleoptera (Insecta), insbesondere der Adephaga. Verh. Naturwiss. Ver. Hamburg NF 31: 1-164.

Beutel R.G. 1999: Phylogenetic analysis of Myxophaga (Coleoptera) with a redescription of Lepicerus horni (Lepiceridae). Zool. Anz. 237[1998]: 291-308.

Beutel R.G. \& HaAs A. 1998: Larval head morphology of Hydroscapha natans LeConte, 1874 (Coleoptera, Myxophaga, Hydroscaphidae) with special reference to miniaturization. Zoomorphology 18: 103-116.

Beutel R.G. \& HaAs F. 2000: Phylogenetic relationships of the suborders of Coleoptera (Insecta). Cladistics 16: 103-141.

Beutel R.G. \& PoHL H. 2004: Head structures of males of Strepsiptera (Hexapoda) with emphasis on basal splitting events within the order. J. Morph., online (2. Dec. 2004).

Beutel R.G., Maddison D.R. \& HaAs A. 1998: Phylogenetic analysis of Myxophaga (Coleoptera) using larval characters. Syst. Entomol. 24: 1-23.

Beutel R.G., Anton E. \& Bernhard D. 2001: Head structures of adults of Spercheus (Coleoptera: Spercheidae): their function and possible significance to staphyliniform phylogeny. Ann. Zool. (Warszawa) 51: 473-484.

BLACKWELDER R.E. 1944: Checklist of the coleopterous insects of Mexico, Central America, the West Indies, and South America. Bull. U. S. Nat. Mus. 185: 1-188.

Costa Lima A. DA 1953: Coleôpteros. 2a parte. In: Insectos do Brasil 7. Escola Nacional de Agronomia, Rio de Janeiro, 323 pp.

CROwson R.A. 1955: The Natural Classification of the Families of Coleoptera. Nathaniel Lloyd, London, 187 pp., 212 Figs.

Darlington P.J. 1950: Paussid Beetles. Trans. Am. Entomol. Soc. 76: 47-142.

FoRBES W.T.M. 1926: The wing folding pattern of the Coleoptera. J. N.Y. Entomol. Soc. 34: 42-115, pls 7-18.

HANSEN M. 1997: Phylogeny and classification of the staphyliniform beetle families. Biol. Skrift. 40: 1-367.

Hörnschmeyer T., Beutel R.G. \& Pasop F. 2002: Head structures of Priacma serrata LeConte (Coleoptera, Archostemata) inferred from x-ray tomography. J. Morph. 252: 298-314.

KÉLER S. VON 1963: Entomologisches Wörterbuch. Akademie Verlag, Berlin, 774 pp.

KIREJTSHUK A.G. 1991: Evolution of mode of life as the basis for division of the beetles into groups of high taxonomic rank. In: Advances in Coleopterology. AEC, Barcelona, pp. 249-262.

Kukalová-Peck J. \& Lawrence J.F. 1993: Evolution of the hind wings in Coleoptera. Can. Entomol. 135: 181-258.

KuKalovÁ-Peck J. \& Lawrence J.F. 2004: Relationships among coleopteran suborders and major endoneopteran lineages: evidence from hind wing characters. Eur. J. Entomol. 101: 95-144.

LESCHEN R.A.B. 1993. Evolutionary patterns of feeding in selected Staphylinoidea (Coleoptera): shifts among food textures. In Schaefer C.W. \& Leschen R.A.B. (eds): Functional 
Morphology of Insect Feeding. Proceedings. Thomas Say Publications, ESA, Lanham, pp. 59-104.

NAGEL P. 1979: Aspects of the evolution of myrmecophilous adaptions in Paussinae (Coleoptera, Carabidae). In Boer P.J. den, Thiele H.-U. \& Weber F. (eds.): On the Evolution of Behaviour in Carabid Beetles. Miscellaneous Papers 18, Agricultural University, Wageningen, H. Veenman and Zonen B.V., pp. 15-34.

Navarrete-Heredia J.L., Cortés-Aquilar J. \& Beutel R.G. 2005: New findings on the enigmatic beetle family Lepiceridae (Coleoptera: Myxophaga). Entomol. Abh. 62: 193-201.

Pohl H., Beutel R.G. \& Kinzelbach R. 2005: Protoxenidae fam. n. (Insecta, Strepsiptera) from Baltic amber - a "missing link" in strepsipteran phylogeny. Zool. Scr. 31: 123-134.

Reichardt H. 1973: A critical study of the suborder Myxophaga, with a taxonomic revision of the Brazilian Tor- ridincolidae and Hydroscaphidae (Coleoptera). Arq. Zool. 24: 73-162.

Reichardt H. 1976. Revision of the Lepiceridae (Coleoptera, Myxophaga). Pap. Avulsos Zool. 30: 35-42.

RöBER H. 1942: Morphologie des Kopfes und des Vorderdarmes der Larve und Imago von Sialis flavilatera. Zool. Jb. Anat. 67: 61-118.

Sharp D. 1882: Fam. Cyathoceridae. In: Biologia CentraliAmericana. Insecta, Coleoptera. Vol. I (Part 2). Taylor and Francis, London, pp. 141-144, pl. 4.

Sharp D. \& Muir F. 1912: The comparative anatomy of the male genital tube in Coleoptera. Trans. Entomol. Soc. London 1912: 477-642, + pls 42-78.

SNODGRASS R.E. 1935: Principles of Insect Morphology. McGraw-Hill, New York, 667 pp.

Received November 1, 2004; revised and accepted June 9, 2005 